\title{
Enzyme SU-8 microreactors: simple tools for cell-culture monitoring
}

\author{
Sara Talaei · Peter D. van der Wal · Sher Ahmed · \\ Martha Liley $\cdot$ Nico F. de Rooij
}

Received: 16 May 2014 / Accepted: 9 February 2015 / Published online: 18 February 2015

(C) Springer-Verlag Berlin Heidelberg 2015

\begin{abstract}
Monitoring metabolism fluctuations inside a cell culture is a valuable method for assessment of the cells vitality. Enzyme-based biosensors can provide selective measurement of metabolites such as glucose, lactate, glutamate and choline. However, integration of these biosensors inside a cell culture is a challenging issue that can disrupt the properties of the cells microenvironment or influence the biosensors' enzyme functioning. Herein, a technique for measuring the abovementioned metabolites in a cell culture without affecting the enzymes or the cells is presented. In this study, SU-8 is investigated as a suitable substrate for a simple enzyme immobilization. Two SU-8 microreactors are designed inside a microfluidic cartridge and functionalized with different enzymes. The implemented microreactors are used for detection of two metabolites simultaneously in a few microliters of a sample extracted from the cell-culture medium. Sub-micromolar concentrations are detectable using this device. The results of measuring variations in glucose and lactate concentration inside a cell culture, before and after exposing the cells to three different toxicants, are presented. In order to eliminate the enzymes disruption by the toxicants
\end{abstract}

Electronic supplementary material The online version of this article (doi:10.1007/s10404-015-1562-8) contains supplementary material, which is available to authorized users.

S. Talaei $(\varangle) \cdot$ P. D. van der Wal · N. F. de Rooij

Sensors, Actuators and Microsystems Laboratory (SAMLAB), Institute of Microengineering (IMT), Ecole Polytechnique Fédérale de Lausanne (EPFL), Rue de la Maladière 71B, 2000 Neuchâtel, Switzerland

e-mail: sara.talaei@epfl.ch

S. Ahmed $\cdot$ M. Liley

Centre Suisse d'Electronique et de Microtechnique (CSEM),

Rue Jaquet Droz 1, 2000 Neuchâtel, Switzerland present inside the medium, a protocol for a toxicant-free sampling is investigated.

Keywords SU-8 $\cdot$ Microreactor $\cdot$ Enzyme immobilization $\cdot$ Cell-culture monitoring $\cdot$ Toxin detection

\section{Introduction}

Monitoring the cell metabolism in vitro is one of the most valuable approaches in cell analysis that determines cells vitality, health and population (Yotter and Wilson 2004). Examples of metabolite substances are glucose and lactate, commonly available in most cell types, as well as neurotransmitters, albumin and urea, present in specialized cells. Implementing biosensors inside the cell culture for monitoring the metabolically relevant parameters such as extracellular oxygen $\left(\mathrm{O}_{2}\right)$ and $\mathrm{pH}$ (Martinoia et al. 1993; Thedinga et al. 2007; Wiest et al. 2005), or the concentration of the metabolites (Cheng et al. 2010; Eklund et al. 2004; Kieninger et al. 2012) is a well-known technique. Usually, such biosensors are integrated inside the cell culture and as close as possible to the cells. According to the diffusion profile, by positioning the biosensors closer to the cells, the possibility of measuring small concentrations of the metabolites increases.

Enzymes are extremely helpful for indirect metabolite monitoring. They can be very specific catalysts of reactions involving metabolites and offer the possibility to monitor reaction (by-) products. Monitoring the consumption of $\mathrm{O}_{2}$ (Updike and Hicks 1967) or production of hydrogen peroxide $\left(\mathrm{H}_{2} \mathrm{O}_{2}\right)$ (Frey et al. 2010; Guilbault and Lubrano 1973) is the most common approach when oxidase enzymes (e.g., glucose oxidase (GOx), lactate oxidase (LOx)) are applied. Using enzyme-based biosensors for detecting metabolites 
(e.g., glucose, lactate, urea) inside cell cultures is reported in the literature (Cheng et al. 2006; Ciobanu et al. 2008; Eklund et al. 2004; Kieninger et al. 2012; Yotter and Wilson 2004). However, as explained below, implementing such biosensors inside a cell culture is not a trivial issue.

One of the challenges is to develop an effective simple enzyme immobilization technique. The mostly used techniques include cross-linking (Frey et al. 2010; KoudelkaHep et al. 1997), entrapment of enzymes (Narang et al. 1994; Tian et al. 2009) and covalent attachment (Drott et al. 1998; Laurell and Rosengren 1994; Strike et al. 1994).

Immobilization of the enzymes by covalent binding or nonspecific adsorption onto the bare surface of a material provides a direct contact between the enzyme and the sample. Therefore, it is more efficient compared to the methods in which the enzyme is entrapped in a matrix, and the analytes need to penetrate through the matrix for reaching the enzyme. One of the surfaces that can be used for covalent bonding of enzymes is SU-8. SU-8 is a standard epoxy-based photoresist, which is especially suitable for creating high-aspect ratio structures with a thickness from a few micrometers up to several hundred micrometers. The immobilization of certain biomolecules on SU-8 has been reported (Blagoi et al. 2008; Deepu et al. 2009; Joshi et al. 2007; Marie et al. 2006; Yang et al. 2007).

Previously, we introduced a simple technique for immobilization of enzymes on SU-8 surface without the need for pretreatment of the surface (Talaei et al. 2010, 2011, 2012). A similar method was reported for immobilization of enzymes on other photoresists as well as SU-8 (Thomas et al. 2011). In addition to the physisorption, the key point exploited for the immobilization of enzymes on a SU-8 surface is the fact that the cross-linking reaction is not complete, and residual epoxy groups still remain after curing. The presence of these epoxy groups was demonstrated using Fourier transform infrared spectroscopy (FTIR) of SU-8 (Blagoi et al. 2008). These epoxy groups can react with amino, hydroxyl or carboxyl groups (Vasylieva et al. 2011). Enzymes are protein molecules constituted of amino acids and therefore exhibit amino (e.g., lysine) and carboxyl groups (e.g., glutamic acid). Thus, SU-8 is potentially a suitable substrate for bonding to enzymes.

One of the drawbacks of integrating enzyme-based biosensors inside the cell culture is that when the sensing electrodes are in contact with the cell-culture medium, the (by-) products (e.g., $\mathrm{H}_{2} \mathrm{O}_{2}$ ) can diffuse into the cell-culture bulk medium and affect the cells. Also, in case of implementing more than one enzyme-based biosensor, cross-talk between the adjacent electrodes is a problem. Furthermore, the applied voltage can influence the viability of the cells (Koyama and Aizawa 2008). Another drawback is related to the electrodes material composition. Often $\mathrm{Ag} / \mathrm{AgCl}$ is applied as a pseudo-reference electrode. For many cell types, silver ions are toxic in $\mathrm{nM}$ concentrations (Cheng et al. 2010).

In cases the cells are used for applications such as environmental monitoring, toxicology or drug testing, there is a high possibility that the cells are exposed to chemical components that can interfere with the enzyme functioning and thus disrupt the metabolite detection.

In amperometric enzyme-based biosensing, microreactors have been introduced as beneficial tools for increasing the sensitivity of the biosensors. A microreactor is a miniaturized reaction unit that in a sensing system can act as a concentrator for the measurable (by-) products such as $\mathrm{H}_{2} \mathrm{O}_{2}$. By increasing the residence time of a sample inside a microreactor, the (by-) product is accumulated before the measurement. This technique is especially useful for decreasing the limit of detection when measuring low concentrations of analytes is necessary. During the last decades, several microreactors have been investigated (Drott et al. 1998; Laurell and Rosengren 1994; Strike et al. 2000, 1994; Vojinović et al. 2005). The fabrication of most of these microreactors is relatively complex, and often, the immobilization of the enzyme requires multiple steps. Furthermore, these microreactors are not adapted for simultaneous measurement of multiple analytes.

In this paper, we introduce and characterize a cost-effective and easy-to-fabricate enzyme-based microreactor cartridge that can measure two analytes simultaneously without any cross-talk. It offers the ability to measure analytes in very low concentrations (i.e., $<5 \mathrm{nM}$ ). Similar low limit of detection has not been presented in the literature before. Two parallel SU-8 microreactors are integrated in this cartridge. Each microreactor consists of a microchannel with pillars for increasing the surface area. Enzymes are directly immobilized on the SU-8 surface. We demonstrate the application of the cartridge in monitoring the metabolism of living cells by measuring the metabolites in a small volume of sample $(<300 \mu \mathrm{l})$ extracted from the cell-culture medium. Furthermore, toxicity tests are performed measuring glucose and lactate inside the medium in both standard conditions and after exposing the cells to three different environmental toxicants. This device enables measuring the metabolites in vitro without inserting biosensors inside the cell culture. To abolish the effect of the toxicants present inside the medium on the immobilized enzymes, an appropriate protocol for culture medium sample preparation was investigated.

\section{Cartridge design}

A schematic design of the cartridge is shown in Fig. 1. For monitoring two analytes at the same time, two identical SU-8 microreactors are implemented inside the cartridge 


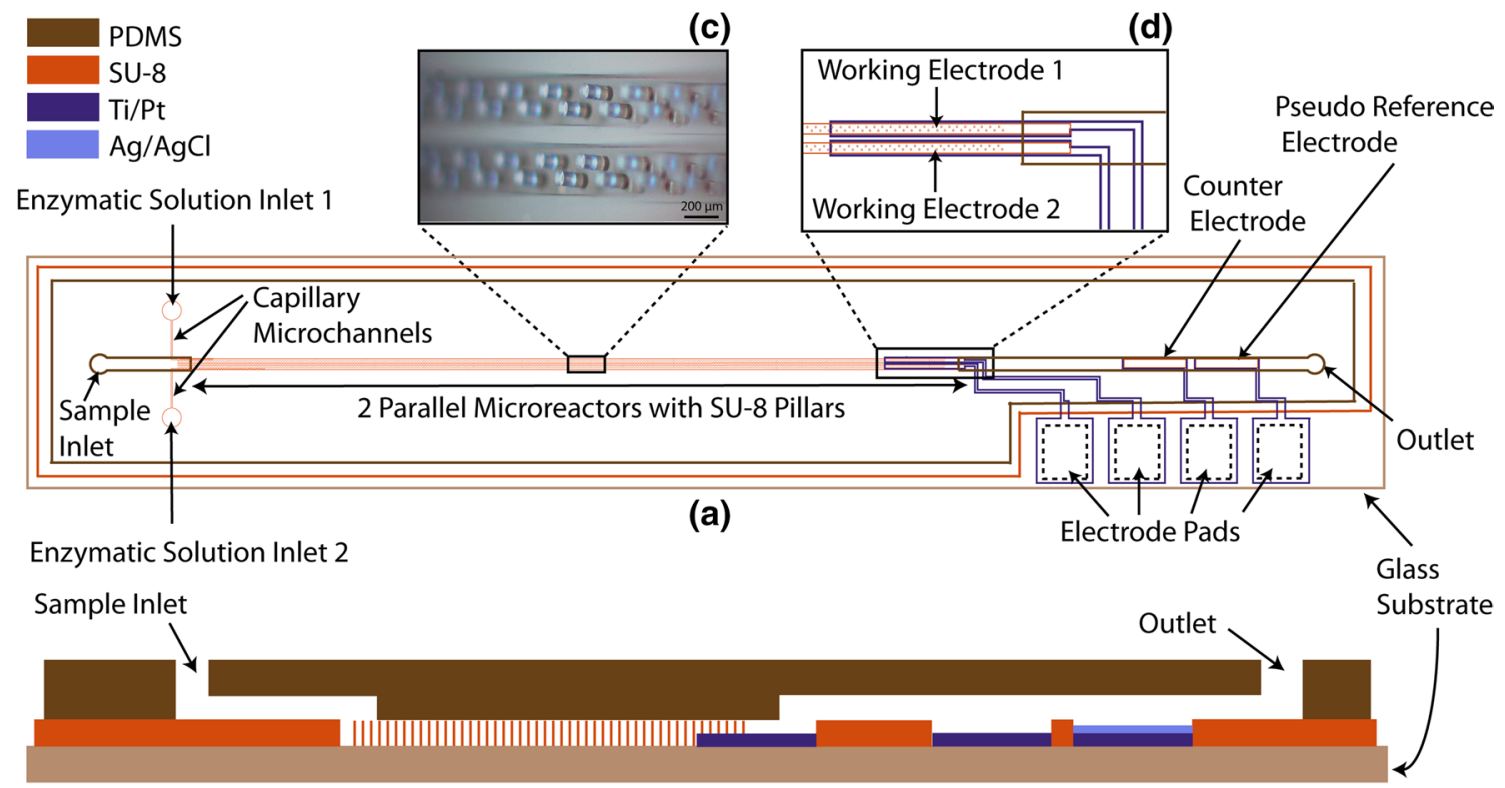

(b)

Fig. 1 Schematic design of the cartridge a top view, $\mathbf{b}$ cross section along one of the parallel microreactors, $\mathbf{c}$ photo of SU-8 pillars inside the parallel microreactors, $\mathbf{d}$ magnified image of the working electrodes inside the SU-8 microreactors

(Talaei 2013). The microreactors are 4.9-cm-long microchannels with a width of $300 \mu \mathrm{m}$ containing 240 pillars with a diameter of $80 \mu \mathrm{m}$ patterned in SU-8 on a glass substrate and covered by a polydimethylsiloxane (PDMS) layer. Two different oxidase enzymes were immobilized separately in each microreactor by dispensing a few microliters of the enzyme solution (described in Sect. 3.3) in the corresponding inlets shown in Fig. 1a. The solution was directed to the microreactors through the capillary microchannels. The $800-\mu \mathrm{m}$-wide microchannel designed in the PDMS layer $(\sim 2 \mathrm{~mm}$ thick) directs the sample toward the microreactors and subsequently over the microelectrodes. Two microelectrodes $(300 \mu \mathrm{m} \times 5 \mathrm{~mm})$ functioning as working electrode are located at the end of each microreactor (Fig. 1d). Localizing the working electrodes in separated parallel microreactors prevents any cross-talk between the parallel microelectrodes. Downstream, a common $\mathrm{Pt}$ counter electrode $(700 \mu \mathrm{m} \times 4 \mathrm{~mm})$ and $\mathrm{Ag} / \mathrm{AgCl}$ pseudo-reference electrode $(700 \mu \mathrm{m} \times 4 \mathrm{~mm})$ are located. $\mathrm{H}_{2} \mathrm{O}_{2}$ is oxidized at the working electrodes polarized at $0.7 \mathrm{~V}$ versus the $\mathrm{Ag} / \mathrm{AgCl}$ pseudo-reference electrode, and the induced current is recorded.

To increase the efficiency of the immobilized enzyme's functionality, the contact surface between the SU-8 pillars and the sample needs to be maximized. A microfluidic simulation of the sample velocity in the microreactor was performed using COMSOL software (version 4.1a). Figure 2 demonstrates the 2D simulated sample velocity gradient at $100 \mu \mathrm{l} / \mathrm{min}$. The simulation graph reveals that the flow is mainly meandering between the pillars and has zones with lower velocity on the outside of the channel and in the shadow of the pillars. By decreasing the flow rate, the zones with lower velocity around the pillars become larger, causing the exchange of analytes and products to/ from the enzyme to be less efficient. This leads to a larger response time of the cartridge at lower sample flow rates. Therefore, to increase the efficiency of the immobilized enzymes, a rearrangement in the design of the microreactors (e.g., width of the microreactor, position of the pillars, etc.) is possible, but not further investigated.

\section{Experimental}

\subsection{Materials}

GOx, LOx, choline oxidase (ChOx), copper chloride $\left(\mathrm{CuCl}_{2} \cdot 2 \mathrm{H}_{2} \mathrm{O}\right)$, ethylenediaminetetraacetic acid (EDTA), penicillin-streptomycin, L-glutamine, nonessential amino acids (NEAA), fetal calf serum (FCS) and propylene glycol monomethyl ether acetate (PGMEA) were purchased from Sigma-Aldrich, Switzerland. L-Glutamate oxidase (GluOx) was purchased from Yamasa Corporation, Japan. For preparation of phosphate-buffered saline (PBS), $9 \mathrm{~g} \mathrm{NaCl}$, $0.368 \mathrm{~g}$ of $\mathrm{NaH}_{2} \mathrm{PO}_{4} \cdot \mathrm{H}_{2} \mathrm{O}$ and $1.367 \mathrm{~g}$ of $\mathrm{Na}_{2} \mathrm{HPO}_{4} \cdot 2 \mathrm{H}_{2} \mathrm{O}$, all obtained from Merck, were dissolved in one liter of DI-water. The $\mathrm{pH}$ was adjusted to 7.2. SU-8 50, PG Remover and LOR 3B were purchased from Microchem 


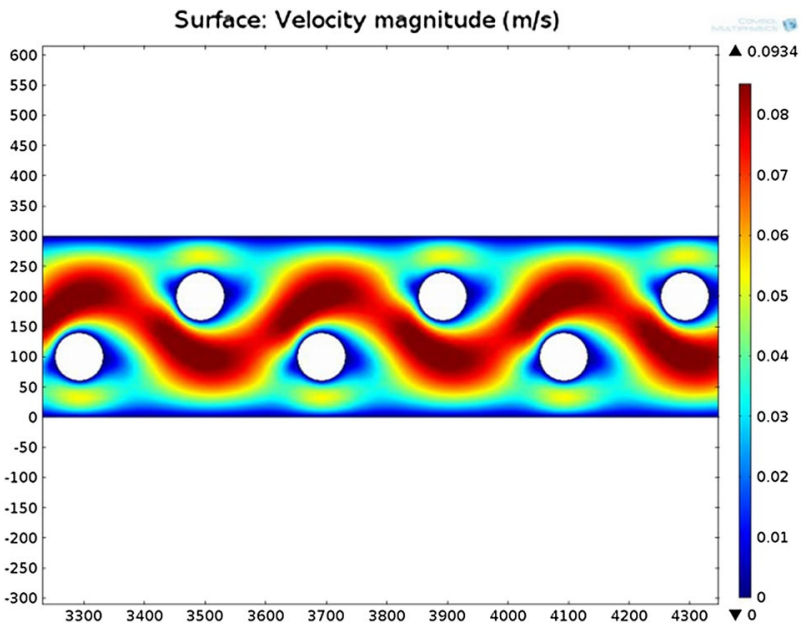

Fig. 2 Simulated velocity gradient in one of the microreactors at sample flow rate of $100 \mu \mathrm{l} / \mathrm{min}$

Corporation, USA. For calibration solutions, D-(+)-glucose anhydrous, sodium L-lactate, choline chloride and L-glutamic acid monosodium salt monohydrate were purchased from Fluka, Switzerland, and dissolved in the PBS solution. Triton X 100 was purchased from Fluka. PDMS Sylgard 184 resin and hardening agent were acquired from Dow Corning, USA. S1813 was obtained from Shipley, USA. High-glucose Dulbecco's modified Eagle's medium (DMEM) purchased from Life Technologies (USA). Silver GLO $^{\mathrm{TM}} 3 \mathrm{~K}$ electrolyte (plating bath) was purchased from Shipley (USA). $\mathrm{FeCl}_{3}$ was purchased from Fluka, Switzerland. $\mathrm{CaCo}-2$ clone (C2Bbe1) cells were purchased from ATCC, USA.

\subsection{Fabrication process}

The first fabrication step was to pattern Ti/Pt electrodes on a $500-\mu \mathrm{m}$-thick glass wafer using a lift-off process. The procedure was as follows: The glass wafer was dehydrated at $200{ }^{\circ} \mathrm{C}$ overnight and spin-coated with photoresists LOR 3B and S1813 successively. Using a photolithographic mask, the photoresists were exposed to UV light. Following the development of the photoresists, $20 \mathrm{~nm}$ Ti and $130 \mathrm{~nm}$ Pt layers were deposited on the wafer by physical vapor deposition (PVD). Ti was used as an adhesion layer. Finally, the photoresists were stripped in PG Remover, leaving the metal electrodes on the glass wafer.

SU-8 50 was spin-coated on the wafer to form a $75-\mu \mathrm{m}$-thick layer. Following the soft-bake, the wafer was exposed to UV light using a mask and submitted to a post-exposure bake. Finally, SU-8 was developed using PGMEA. The SU-8 layer forms the microreactor and insulates the Ti/Pt structures except for the electrode and the contact pads. All the process parameters applied for structuring SU-8 were provided by the Microchem Corp. data sheets.

The structured PDMS was replicated from a $100-\mu$ m-thick SU-8 mold that was patterned on a silicon wafer. A mixture of PDMS base and its hardener (10:1 weight ratio) was degassed in a vacuum chamber before casting in the mold. The PDMS mixture poured in the mold was cured at $65^{\circ} \mathrm{C}$ for $2 \mathrm{~h}$ before de-molding.

$\mathrm{The} \mathrm{Ag} / \mathrm{AgCl}$ pseudo-reference electrode was prepared by galvanostatic deposition of silver on the designated $\mathrm{Pt}$ electrode followed by a chemical oxidation in a $10 \mathrm{mM}$ solution of $\mathrm{FeCl}_{3}$ for $30 \mathrm{~s}$. The silver layer was approximately $2-4 \mu \mathrm{m}$ thick partially transformed into $\mathrm{AgCl}$. For Ag deposition, a different structured PDMS layer with an $800-\mu \mathrm{m}$-wide microchannel was used avoiding that the plating solution contacts the enzyme immobilization area.

After mounting the PDMS layer, the cartridge was fixed in a polymethyl methacrylate (PMMA) cartridge holder equipped with the electrical and fluidic connections. Four spring contacts embedded in the top PMMA layer connect the electrode pads to a potentiostat (eDAQ, Australia). The size of the cartridge is $8.3 \times 2.4 \mathrm{~cm}$ (Figure A1 insert 'in ESM').

Before and after each measurement, PBS was pumped through the cartridge for $30 \mathrm{~min}$. In between measurements, the enzyme-modified cartridges were stored at $4{ }^{\circ} \mathrm{C}$.

\subsection{Enzyme immobilization}

Enzymes were immobilized on the SU-8 pillars before mounting the PDMS layer. Four microliters of the enzyme solution in DI-water with an optimized quantity of Triton X-100 was dispensed on the microreactor channel, by means of a pipette, and then left to dry. The nonionic surfactant, Triton X-100, was added to the solution to overcome the hydrophobicity of SU-8 and increase the wettability of the surface. The enzyme solution flows around the pillars covering completely their outer surface. The composition of the four tested enzyme solutions is shown in Table 1. Before the first measurement, the cartridge was kept at $4{ }^{\circ} \mathrm{C}$ for $24 \mathrm{~h}$.

\subsection{Cell-culture preparation}

Caco-2 clone cells were seeded in 24-well plates (Falcon Germany) at a density of $6 \times 10^{4}$ cells $/ \mathrm{cm}^{2}$ for 21 days until fully differentiated. Cells were cultured in $1.5 \mathrm{ml}$ high-glucose DMEM supplemented with $10 \%$ FCS, $1 \%$ NEAA, $1 \%$ L-glutamine and $1 \%$ penicillin/streptomycin. The culture medium was changed every 2 days. In order to test the effect of the toxicants, the old culture medium was first removed and cells were washed once with PBS. 
Table 1 Composition of the tested enzyme solutions

\begin{tabular}{lllll}
\hline Enzyme name & $\begin{array}{l}\text { Enzyme } \\
\text { activity }\end{array}$ & $\begin{array}{l}\text { Enzyme } \\
\text { quantity }\end{array}$ & $\begin{array}{l}\text { DI-water } \\
(\mu 1)\end{array}$ & $\begin{array}{l}\text { Triton X-100 } \\
(\mathrm{mg})\end{array}$ \\
\hline Glucose oxidase (GOx) & $181 \mathrm{U} / \mathrm{mg}$ & $6 \mathrm{mg}$ & 800 & 1.20 \\
Lactate oxidase (LOx) & $20 \mathrm{U} / \mathrm{mg}$ & $2.5 \mathrm{mg}$ & 800 & 1.20 \\
Choline oxidase (ChOx) & $15 \mathrm{U} / \mathrm{mg}$ & $2.5 \mathrm{mg}$ & 480 & 0.48 \\
Glutamate oxidase (GluOx) & $25 \mathrm{U} / \mathrm{vial}$ & $1 \mathrm{vial}$ & 1500 & 0.25 \\
\hline
\end{tabular}

Consequently, the cell culture was refilled with the regular cell-culture medium containing the toxicant.

\subsection{Cell-culture medium sample preparation}

For proof of concept, the regular metabolism of the cells under standard conditions over time, and also after exposing the cells to three different toxicants, Triton X-100, $\mathrm{CuCl}_{2}$ and acetaminophen, was evaluated. In order to lower the concentration of the metabolites inside the culture medium samples down to the linear range of the biosensors, all samples were diluted 20 times before being introduced into the cartridge. Triton X-100 is a widely used surfactant in industrial and household products ( $\mathrm{Li}$ 2008). Several studies have evaluated the effect of this toxicant on different aquatic organisms (Dayeh et al. 2004, 2005; Li 2008). It is mentioned in the introduction (Sect. 1) that enzyme's functionality can be interfered in vicinity of particular molecules. For monitoring the effect of compounds that do not influence the enzymes, the first protocol was to dilute the samples only in PBS (1:19). According to our experiments, twenty times diluted $0.1 \%$ Triton X-100 did not affect the response of the GOx and LOx cartridges to the calibration solutions. Therefore, the first protocol was applied for monitoring the effect of Triton $\mathrm{X}-100(0.1 \%)$. On the other hand, toxicants such as $\mathrm{Cu}^{2+}$ and other trace metal ions can inhibit the enzymes' functionality significantly. Therefore, for monitoring the effect of such compounds, a second protocol was applied. According to this protocol, the samples were diluted in a PBS solution containing dissolved EDTA $(10 \mathrm{mM})$ with an adjusted $\mathrm{pH}$ to 7.2 (1:19). EDTA complexes the trace metal ions, thus decreasing the concentration of free ions. Copper is a natural element that is required by all plants and animals for their normal growth. A natural mechanism in the human liver maintains the copper concentration in a proper range. However, when the concentration exceeds $2 \mathrm{mg} / \mathrm{l}$, it can cause ill effects in some people (Chambers et al. 2010; Queensland Govermental Public Health Guidance Note 2002). Since EDTA can only complex specific types of chemical compounds, a third protocol was investigated for sample preparation. According to the third protocol, first, the toxicant is left in contact with the cells for a defined period of time (e.g., $24 \mathrm{~h}$ as described in Sect. 4.2). The medium is then evacuated; the cells are rinsed twice with PBS and the regular cell-culture medium, and the cell culture is refilled with a fresh medium. After another defined time frame (e.g., $24 \mathrm{~h}$ as described in Sect. 4.2), the sample is extracted from the refilled cell culture. Successively, the sample is diluted in PBS (1:19) and introduced into the cartridge. Following this procedure, the sample reflects the effect of the toxicants without containing them. Moreover, the final dilution process reduces the effect of any residual chemical agents in contact with the enzymes. This protocol was tested for monitoring the effect of acetaminophen on the metabolism of the cells. Acetaminophen is a widely used pain reliever and fever reducer. On the other hand, overdose by this chemical agent is one of the most frequent types of poisoning (National Poisons Information Service Annual Report 2011; Rowden et al. 2005). It is also recognized as an important wastewater contaminant and a persistent organic pollutant in the environment (Kim et al. 2007; Kolpin et al. 2002). Although, a complete removal of the medium and rinsing the cells with PBS is not a suitable instruction for all cell types (e.g., neural cells), it is applicable for many types of cells such as Caco-2 clone cells. Due to the small volume of the required sample for each measurement, miniaturized perfusion-based cell cultures can easily be connected to the microreactor cartridge to provide an on-line monitoring of the cells. A miniaturized integrated cell culture was also designed by the authors and tested following the same protocol executed by an automated system, which will be presented in another article.

\section{Results and discussion}

The results are presented in two main sections. First, in Sect. 4.1, the characterization results of the cartridge and the SU-8 microreactors are presented. Second, in Sect. 4.2, the results of measuring metabolites in Caco- 2 cell cultures using the cartridge are demonstrated. 
Table 2 Cartridge average sensitivity for measuring four analytes in a period of 10 days

\begin{tabular}{lllll}
\hline & Glucose & Lactate & Glutamate & Choline \\
\hline Day 1 & & & $362.5 \mathrm{pA} / \mu \mathrm{M} \pm 33 \%$ & \\
Day 2 & $88.3 \mathrm{nA} / \mathrm{mM} \pm 6 \%$ & $136.9 \mathrm{nA} / \mathrm{mM} \pm 11 \%$ & & $55 \mathrm{pA} / \mu \mathrm{M} \pm 37 \%$ \\
Day 3 & & & $135 \mathrm{pA} / \mu \mathrm{M}+26 \%$ & \\
Day 4 & $35.9 \mathrm{nA} / \mathrm{mM} \pm 9 \%$ & $27.1 \mathrm{nA} / \mathrm{mM} \pm 9 \%$ & & $22.5 \mathrm{pA} / \mu \mathrm{M} \pm 48 \%$ \\
Day 5 & & & $115 \mathrm{pA} / \mu \mathrm{M} \pm 28 \%$ & \\
Day 7 & $19 \mathrm{nA} / \mathrm{mM} \pm 8 \%$ & $17.5 \mathrm{nA} / \mathrm{mM} \pm 12 \%$ & $55 \mathrm{pA} / \mu \mathrm{M} \pm 9 \%$ & \\
Day 10 & $9.3 \mathrm{nA} / \mathrm{mM} \pm 15 \%$ & & & \\
\hline
\end{tabular}

\subsection{Cartridge characterization}

\subsubsection{SU-8 as a platform for enzyme immobilization}

Following the simple, one-step procedure described in Sect. 3.3, four enzymes in two pairs, GOx/LOx and GluOx/ ChOx, were immobilized in the microreactors. The first pair can be used for simultaneous monitoring of glucose consumption and lactate production in cultures with almost all cell types, and the second pair can be used for monitoring the production of glutamate and choline neurotransmitters in neuronal cell cultures. The cartridge was calibrated on successive days after the enzyme immobilization by monitoring the amperometric response of the cartridge to the applied calibration solutions with step-wise increasing analyte concentration (Figure A2 insert 'in ESM'). The linear range for glucose and lactate cartridges was $0.5-4$ and $0.06-0.3 \mathrm{mM}$, respectively. For glutamate and choline biosensors, as the concentrations of interest are in the range of a few $\mu \mathrm{M}$, the concentration was measured from 0.5 to $20 \mu \mathrm{M}$, and a good linearity in this range was observed. The pumping flow rate of all samples was fixed at $50 \mu \mathrm{l} / \mathrm{min}$. The average sensitivity of four cartridges in their linear range is presented in Table 2. A decrease in the sensitivity (ratio of the increase in the generated current to the increase in the analyte concentration) occurred over time. This decrease can be due to the natural degradation of the enzymes and/or the declined enzyme physisorption to the substrate. The SU-8 microreactors of the calibrated cartridges for measuring glucose/lactate and glutamate/choline were structured 6 months and 1 week before the tests, respectively. The effect of SU-8 aging on the cartridge response is further explained in Sect. 4.1.6.

The cross-talk between the adjacent microreactors was tested by applying a PBS solution containing either glucose $(0.5-12 \mathrm{mM})$ or lactate $(0.1-2 \mathrm{mM})$ to the microfluidic cartridge with both GOx and LOx immobilized in the parallel microreactors. The signal recorded by the microelectrode in the GOx microreactor revealed zero concentration of glucose when the applied solution contained no glucose. The same result was obtained by the microelectrode localized in the LOx microreactor when the concentration of lactate in the applied solution was zero (graphs not shown).

\subsubsection{Effect of SU-8 surface area on cartridge sensitivity}

Reducing the surface area of SU-8 inside the microreactors decreased the sensitivity of the cartridges. This experiment verified that the SU-8 surface was directly associated with the immobilization of the enzymes. For example, when the original surface area was reduced to $73 \%$, the sensitivity of the cartridges with immobilized GOx was decreased to $79 \%$. The SU-8 surface area was reduced by removing some of the pillars from the microreactors manually before dispensing the enzyme solution. Due to the imperfect removal of the pillars, some SU-8 residuals remained on the substrate which were not counted in the calculation of the surface area. Furthermore, the removal of the pillars slightly decreased the local velocity of the sample within the microreactor, which was not compensated in this experiment. Lower velocities in the microreactor increase the sensitivity of the cartridge (see Sect. 4.1.4).

\subsubsection{Effect of enzyme quantity on cartridge sensitivity}

In order to investigate the influence of the dispensed amount of enzyme on the cartridge sensitivity, the enzyme solutions with different enzyme concentrations were applied to the microreactors. Two days after the enzyme immobilization, the response of the cartridges to the calibration solutions pumped at the constant flow rate of $50 \mu \mathrm{l} / \mathrm{min}$ was recorded. Figure 3 is a typical graph showing the average results of glucose measurement using four identical cartridges with different amounts of immobilized GOx. The error bars represent the standard deviations around the average value. When the concentration of GOx in the applied enzyme solutions was zero, the response of the cartridge to different concentration of glucose was close to zero with negligible fluctuations. A $22.5 \%$ increase in the sensitivity of the biosensors was observed as the amount of GOx concentration in the enzymatic solution was increased tenfold (inset of Fig. 3).

\subsubsection{Effect of flow rate on cartridge response}

As it is explained in the cartridge design (Sect. 2), at higher flow rates, the sample residence time inside the 


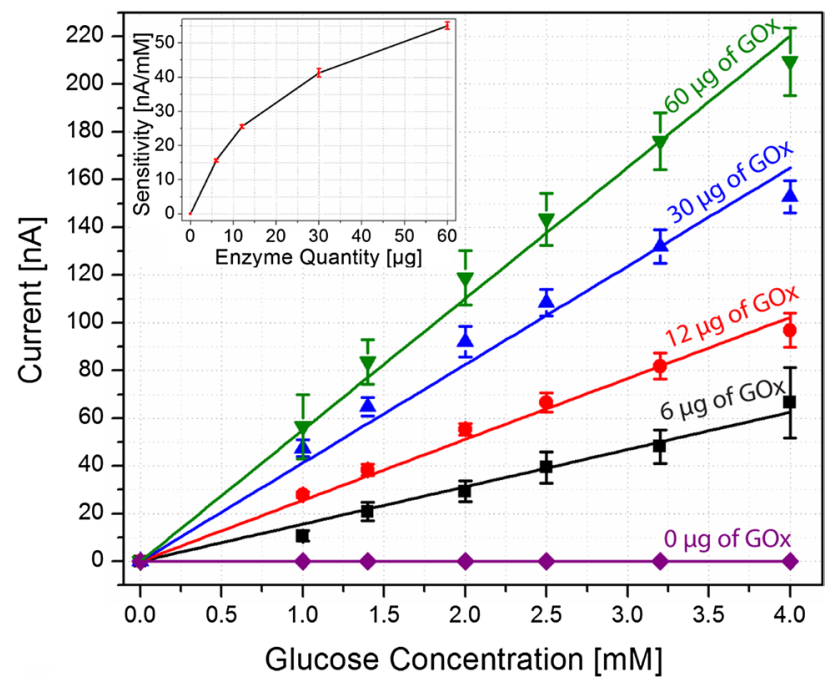

Fig. 3 Effect of enzyme quantity on the cartridge response. The main graph shows the response of the cartridge to glucose concentrations when different amounts of GOx were immobilized in the microreactors. The inset shows the effect of the enzyme quantity on the sensitivity of the cartridge

microreactor is shorter. Therefore, the concentration of the produced $\mathrm{H}_{2} \mathrm{O}_{2}$ is lower. As a result, the sensitivity of the cartridge decreases at higher flow rates. On the other hand, at lower flow rates, the slower transfer of analytes and products to/from the immobilized enzymes causes a longer response time. The average response of four cartridges with immobilized GOx for measuring glucose concentrations in the calibration solutions is shown in Fig. 4 as the samples were pumped at three different flow rates. Increasing the pumping flow rate from 25 to $100 \mu \mathrm{l} / \mathrm{min}$, decreased the sensitivity gradually (Fig. 4a). However, as it is shown in Fig. 4 b, by increasing the sample flow rate, the response time of the biosensors is shorter compared to the experiments performed at lower flow rates. The graph in Fig. 4b is obtained when each of the four calibration solutions was pumped through the cartridge for $7 \mathrm{~min}$, successively. The response time $\left(t_{90}\right)$ of the cartridge was $\sim 3, \sim 4$ and $\sim 13 \mathrm{~min}$ when, respectively, the sample was pumped at 100,50 and $25 \mu \mathrm{l} / \mathrm{min}$.

\subsubsection{Stopped-flow measurements}

In the "effect of flow rate on the cartridge response" (Sect. 4.1.4), it is explained that at lower flow rates, more $\mathrm{H}_{2} \mathrm{O}_{2}$ is accumulated inside the microreactor. Stopping the flow underlies a further concentration of $\mathrm{H}_{2} \mathrm{O}_{2}$. Therefore, stopping the flow inside the microreactor is a useful technique for increasing the signal level for detection of very low concentrations. For instance, using this protocol, it was investigated that glutamate neurotransmitter can be
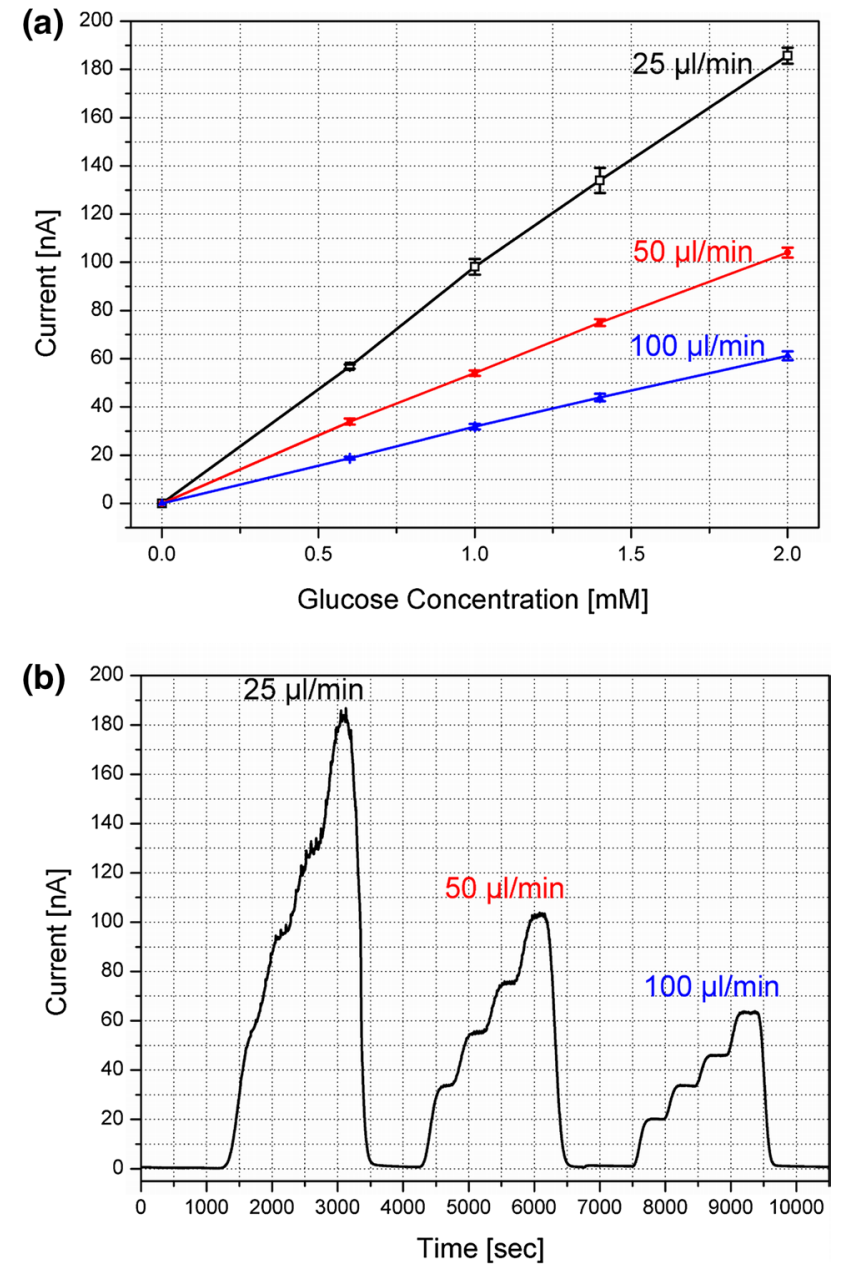

Fig. 4 Effect of flow rate on the cartridge response when GOx was immobilized $\mathbf{a}$ increase in the sensitivity by lowering the flow rate, $\mathbf{b}$ higher response levels and longer response times at lower flow rates

measured in concentrations $<1 \mathrm{nM}$, while in the literature, to the best of our knowledge, the minimum reported detection limit is $7-15 \mathrm{nM}$ (Niwa et al. 1997). Figure 5 shows the results of measuring low concentrations using the stopped-flow protocol in cartridges after immobilization of four different enzymes in the microreactors. As it is explained in Sect. 4.1.6, depending on the SU-8 substrate, the deviation of the cartridges response around the average value can be negligible $(<2 \%)$. Therefore, in Fig. 5 for a better visibility, the error bars are not shown. Each sample was first pumped into the cartridge at $50 \mu \mathrm{l} / \mathrm{min}$; the flow was stopped for $2 \mathrm{~min}$ and then started again at $50 \mu \mathrm{l} /$ min. Upon the time the pump is stopped, the accumulated $\mathrm{H}_{2} \mathrm{O}_{2}$ can still diffuse to the working electrode. Thus, there is a gradual increase in the current after stopping the flow. As soon as the pump is started again, all produced $\mathrm{H}_{2} \mathrm{O}_{2}$ molecules are pushed toward the microelectrodes quickly, and as a result, a large peak forms in the response 

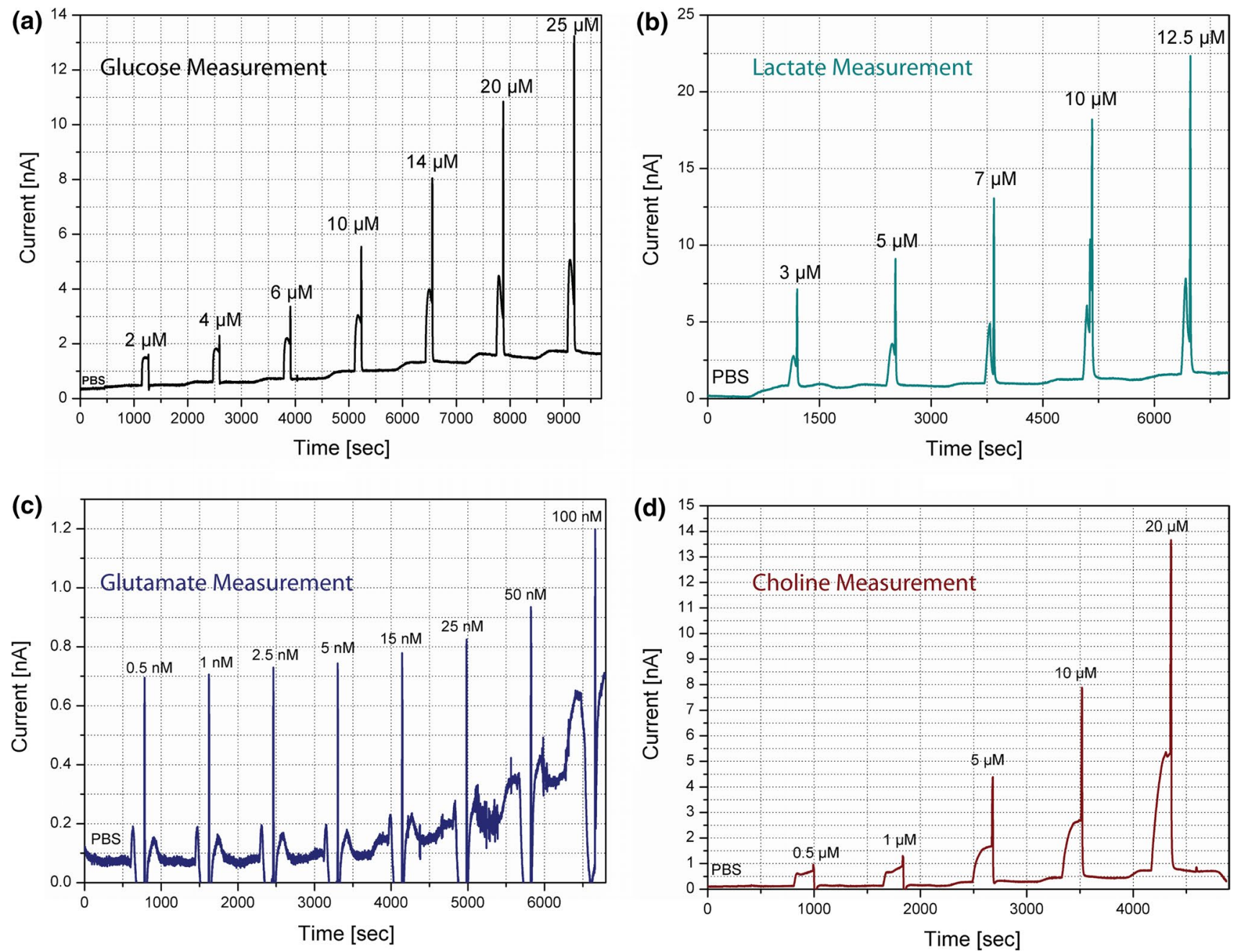

Fig. 5 Using the stopped-flow protocol for measuring low concentrations. Each graph corresponds to the cartridge response with the following enzymes immobilized in the SU-8 microreactors: a GOx, b LOx, c GluOx, d ChOx

signal (Figure A3 insert 'in ESM'). The corresponding current value of each peak is proportional to the analyte concentration.

\subsubsection{Effect of $S U-8$ aging and baking conditions on the cartridge response}

It was observed that the response of the cartridges with older SU-8 structures was more stable than the ones with SU-8 structures fabricated a few days or weeks before the enzyme immobilization. In other words, measuring an analyte concentration repeatedly in a few hours using younger SU-8 structures showed a non-negligible reduction in the cartridge response level. On the other hand, the response of the older fabricated cartridges was almost stable in repetitive measurements. The results imply that less enzyme bonds covalently to the SU-8 surface in younger structures, and the enzyme physiosorption to the surface can be gradually decreased over time by rinsing the surface.

In addition to the improved stability in the cartridge response by aging, the average sensitivity of the cartridges with older SU-8 structures (6 months old) was slightly higher $(8.7 \%)$ than the ones with fresher structures (1 week old). Furthermore, a better reproducibility was observed in the response of the cartridges with older SU-8 structures. A similar effect was observed in the response of the cartridges that were submitted to a hard bake $\left(48 \mathrm{~h}\right.$ at $\left.70{ }^{\circ} \mathrm{C}\right)$ before the enzyme immobilization. After the hard bake, a $15.4 \%$ increase in the average sensitivity of the cartridges was observed. Hard bake of SU-8 affects the structures in a similar manner to aging. Both techniques result in a more stable response and a higher average sensitivity of the cartridge. This can be due to a better bonding capability of cured SU-8 structures (by aging or baking) to enzymes. 
Fig. 6 Response of the microreactor cartridge upon measuring glucose and lactate in the cell-culture medium a glucose and lactate metabolism in a period of 5 days without adding toxicants. Effect of 24-h exposure of the cells to $\mathbf{b}$ $0.1 \%$ Triton X-100, c 5 ppm and $10 \mathrm{ppm} \mathrm{CuCl}_{2}, \mathbf{d} 20,30$ and $50 \mathrm{mM}$ acetaminophen
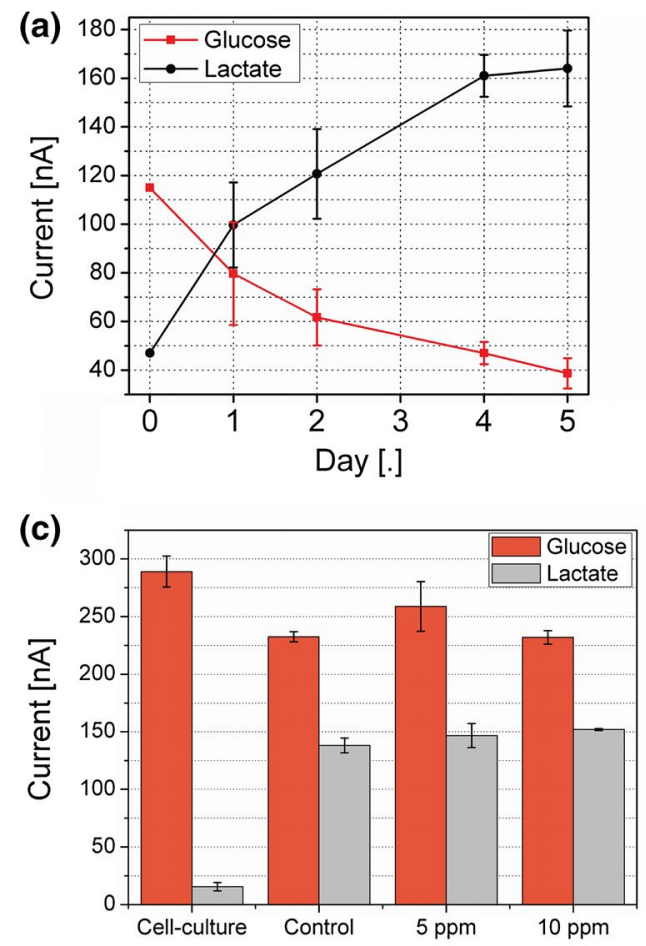
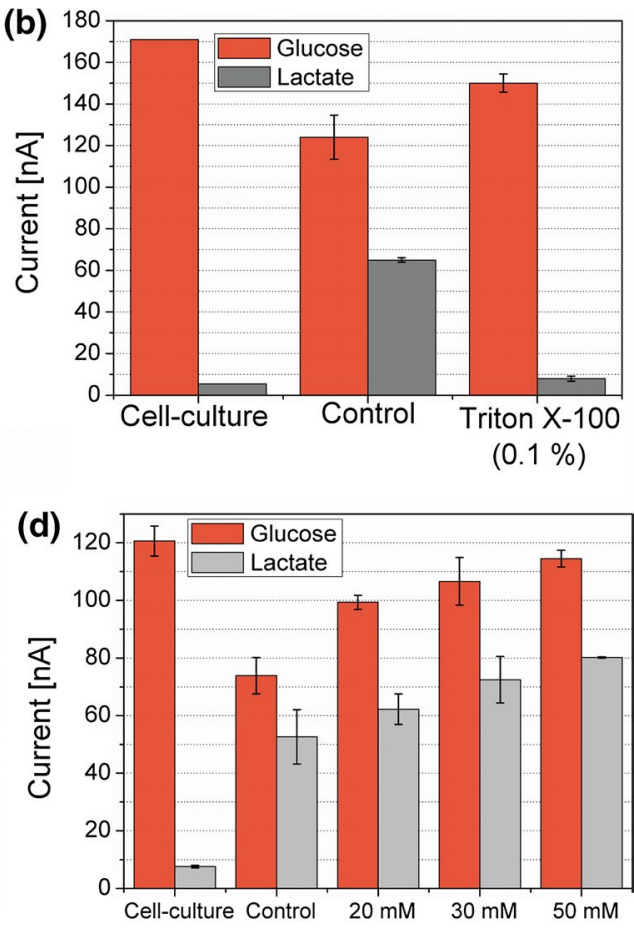

\subsection{Functionalized microreactors for monitoring cells' metabolism in vitro}

For demonstrating the application of the cartridge in monitoring the metabolism of living cells, the concentrations of glucose and lactate as two important metabolites were measured in the culture medium of Caco- 2 clone cells before and after exposing the cells to different concentrations of toxicants. The results of on-line monitoring the concentration of glutamate and choline in neuronal cell cultures will be presented in a future paper.

Caco- 2 cells are intestinal epithelial cells that are usually cultivated on permeable filters forming a monolayer. This type of cell line is well developed as an in vitro model of the intestinal epithelial barrier, especially in pharmaceutical industry for studying the drugs transport across the layer (Artursson et al. 2001).

For each test, $300 \mu \mathrm{l}$ of the culture medium was extracted from the cell culture and pretreated as according to the protocols explained in Sect. 3.5. The cartridge was calibrated before and after each test. The average value and the standard deviation (shown with error bars) of three measurements obtained in these experiments are demonstrated in Fig. 6. Similar results were obtained using the integrated perfusion-based microfluidic cell culture.

Figure $6 a$ shows the results of measuring the glucose consumption and lactate production by the cells using the cartridge over a period of 5 days for monitoring the cell's regular metabolism. As expected, under standard conditions, a decrease in glucose concentration and an increase in lactate concentration of the cell-culture medium were recorded. The toxic effect of surfactants on living cells is mainly due to a disruption they cause on the cell membrane integrity. The results of monitoring the effect of $0.1 \%$ Triton X-100 surfactant on the metabolism of Caco-2 cells, $24 \mathrm{~h}$ after the exposure, are presented in Fig. 6b. The concentrations of glucose and lactate in the standard culture medium before seeding the cells were measured $19.1 \pm 4.1$ and $0.5 \pm 21.3 \% \mathrm{mM}$, respectively. After $24 \mathrm{~h}$, in the control cell culture in which no toxicant was added, the concentration of glucose decreased to $13.8 \pm 8.5 \% \mathrm{mM}$, and the concentration of lactate increased to $6.5 \pm 1.7 \% \mathrm{mM}$. However, in the test cell culture containing Triton X-100, as the cell membrane was disrupted, the viability of the cells was dropped quickly. As a result, $24 \mathrm{~h}$ after the exposure, the consumption of glucose and the production of lactate in test medium decreased for almost 55 and $95 \%$, respectively, compared to the control medium.

The cells were also exposed to two different concentrations of $\mathrm{CuCl}_{2}$ (i.e., 5 and $10 \mathrm{ppm}$ ), and the second protocol for pretreatment of the samples described in Sect. 3.5 was applied. Figure $6 \mathrm{c}$ demonstrates the amperometric measurement results. Before seeding the cells, the concentration of glucose and lactate was $19.2 \pm 4.6$ and $0.6 \pm 23.6 \% \mathrm{mM}$, respectively. After $24 \mathrm{~h}$ without applying any $\mathrm{CuCl}_{2}$, the concentration of glucose in the control cell culture was reduced to $15.5 \pm 1.9 \% \mathrm{mM}$, while the concentration of lactate was increased to $5.5 \pm 4.5 \% \mathrm{mM}$. When $\mathrm{CuCl}_{2}$ 
was applied to the cell cultures for $24 \mathrm{~h}$, a slight increase in the lactate production of the samples was observed compared to the control samples that were not contaminated. This increase was slightly higher when $10 \mathrm{ppm} \mathrm{CuCl}_{2}$ was applied compared to $5 \mathrm{ppm}$ (i.e., $10.9 \%$ increase compared to $5.4 \%)$. The glucose consumption was decreased only when 5 ppm of $\mathrm{CuCl}_{2}$ was applied. In this condition, compared to the control medium, almost $46 \%$ reduction in the glucose consumption was observed. However, based on the measurement values and their variations as indicated by the error bars, we conclude that 24-h contamination of Caco-2 clone cells to 5 and 10 ppm of copper does not have a significant impact on their metabolism rate of glucose and lactate.

Acetaminophen inhibits the mitochondrial respiration. As a result, the intake of glucose by the cells will decrease, and more lactate is produced by fermentation (Chacey et al. 2012; Shah et al. 2011). The cells were exposed to three different concentrations of acetaminophen (20,30 and $50 \mathrm{mM}$ ) for $24 \mathrm{~h}$. Following our third presented protocol explained in Sect. 3.5, the results of glucose and lactate measurements using the cartridge $24 \mathrm{~h}$ after removing the toxicants and refilling the cell cultures by a fresh medium are shown in Fig. 6d. By increasing the concentration of acetaminophen inside the cell culture, glucose consumption of the cells was reduced while lactate production was increased.

As it is described in the introduction (Sect. 1), conventional enzyme-based biosensors developed for on-line monitoring of cell cultures [e.g., (Kieninger et al. 2012)] are not capable of simultaneous concentration measurement of more than one metabolite without cross-talk. Moreover, due to the possible disruptive effect of toxicants on enzymes, to the best of our knowledge, no enzyme-based biosensor has been reported for monitoring the effect of interfering toxicants such as acetaminophen on the metabolism of cells in vitro.

\section{Conclusions}

We investigated the capability of the widely used SU-8 photo resist as a platform for a simple and quick enzyme immobilization. Design, characterization and application of SU-8 microreactors that offer the possibility of detecting low concentrated analytes are demonstrated in this paper. By functionalizing SU-8 microreactors with enzymes, and implementing them inside a microfluidic cartridge for amperometric measurement of metabolites, a simple novel technique for on-line monitoring of living cells metabolism is revealed. Measuring the metabolites inside cell-culture medium by integrating enzyme-based biosensors inside the cell culture is a challenging issue. Diffusion of the enzymatic reaction (by-) products into the cell-culture bulk, the cross-talk between the adjacent biosensors, perturbation of toxic components inside the culture medium on enzymes functioning and disrupting effects of the electrodes in contact with the cells are the main challenges. We demonstrated that the concentration of two metabolites such as glucose and lactate inside the cell-culture medium can be measured simultaneously by the presented cartridge with a good precision without the need for implementing the biosensors inside the cell culture. Monitoring the metabolism of the cells while they are stimulated chemically is of significant importance, especially in environmental monitoring, toxicology and development of pharmaceutical products. In such applications, the cells are exposed to samples that can contain components, which can impose toxic features on the enzymes. Therefore, in order to enable the presented enzyme-based microfluidic cartridge for monitoring the cells influenced by various samples, the possibility of having contaminations by unknown chemical components that can potentially cause perturbations in the enzymes functioning was considered. We ruled out this prospect by determining a protocol for sample preparation before exposing the cartridge. The results of metabolism screening of Caco- 2 clone cells before and after being stimulated by three different toxicants are presented to demonstrate a beneficial utility of the cartridge and the protocol.

Acknowledgments The authors gratefully thank the staff at the "Microsystems Technology Division" of the CSEM for their technical assistance. Many thanks to Marta Giazzon at CSEM for the valuable comments on the cell culture experiments. This research was supported by the NanoTera "Livesense" project funded by the "Swiss National Science Foundation" (SNSF).

\section{References}

Artursson P, Palm K, Luthman K (2001) Caco-2 monolayers in experimental and theoretical predictions of drug transport. Adv Drug Deliv Rev 46:27-43. doi:10.1016/S0169-409X(00)00128-9

Blagoi G, Keller S, Johansson A, Boisen A, Dufva M (2008) Functionalization of SU-8 photoresist surfaces with IgG proteins. Appl Surf Sci 255:2896-2902. doi:10.1016/j.apsusc.2008.08.089

Chacey MD, Crosser MS, Crouser ED (2012) Metabolic acidosis in acetaminophen overdose without concurrent liver toxicity. Kansas J Med 5(1):12-18

Chambers A et al (2010) An exposure-response curve for copper excess and deficiency. J Toxicol Environ Health B Crit Rev 13:546-578. doi:10.1080/10937404.2010.538657

Cheng W, Klauke N, Sedgwick H, Smith GL, Cooper JM (2006) Metabolic monitoring of the electrically stimulated single heart cell within a microfluidic platform. Lab Chip 6:1424-1431

Cheng W, Klauke N, Smith G, Cooper JM (2010) Microfluidic cell arrays for metabolic monitoring of stimulated cardiomyocytes. Electrophoresis 31:1405-1413. doi:10.1002/elps.200900579

Ciobanu M, Taylor DE, Wilburn JP, Cliffel DE (2008) Glucose and lactate biosensors for scanning electrochemical microscopy imaging of single live cells. Anal Chem 80:2717-2727. doi:10.1021/ ac7021184

Dayeh VR, Chow SL, Schirmer K, Lynn DH, Bols NC (2004) Evaluating the toxicity of Triton X-100 to protozoan, fish, and mammalian 
cells using fluorescent dyes as indicators of cell viability. Ecotoxicol Environ Saf 57:375-382. doi:10.1016/s0147-6513(03)00083-6

Dayeh VR et al (2005) Comparing a ciliate and a fish cell line for their sensitivity to several classes of toxicants by the novel application of multiwell filter plates to Tetrahymena. Res Microbiol 156:93-103. doi:10.1016/j.resmic.2004.08.005

Deepu A, Sai VVR, Mukherji S (2009) Simple surface modification techniques for immobilization of biomolecules on SU-8. J Mater Sci Mater Med 20:25-28. doi:10.1007/s10856-008-3471-9

Drott J, Lindström K, Rosengren L, Laurell T (1998) Porous silicon as the carrier matrix in a micro enzyme reactor to achieve a highly efficient and long-term stable glucose sensor. In: Ehrfeld W (ed) Microreaction technology. Springer, Berlin, pp 175-182. doi:10.1007/978-3-642-72076-5_20

Eklund SE, Taylor D, Kozlov E, Prokop A, Cliffel DE (2004) A microphysiometer for simultaneous measurement of changes in extracellular glucose, lactate, oxygen, and acidification rate. Anal Chem 76:519-527. doi:10.1021/ac034641z

Frey O, Talaei S, van der Wal PD, Koudelka-Hep M, de Rooij NF (2010) Continuous-flow multi-analyte biosensor cartridge with controllable linear response range. Lab Chip 10:2226-2234. doi: $10.1039 / \mathrm{c} 004851 \mathrm{~h}$

Guilbault GG, Lubrano GJ (1973) An enzyme electrode for the amperometric determination of glucose. Anal Chim Acta 64:439455. doi:10.1016/S0003-2670(01)82476-4

Joshi M, Pinto R, Rao VR, Mukherji S (2007) Silanization and antibody immobilization on SU-8. Appl Surf Sci 253:3127-3132. doi:10.1016/j.apsusc.2006.07.017

Kieninger J, Tamari Y, Enderle B, Sandvik JA, Pettersen EO, Urban GA (2012) Cell culture monitoring with integrated biosensors for novel insights into metabolic pathways in tumor cells. Biosensors Conference XXII Proc, Mexico

Kim Y, Choi K, Jung J, Park S, Kim PG, Park J (2007) Aquatic toxicity of acetaminophen, carbamazepine, cimetidine, diltiazem and six major sulfonamides, and their potential ecological risks in Korea. Environ Int 33:370-375. doi:10.1016/j.envint.2006.11.017

Kolpin DW, Furlong ET, Meyer MT, Thurman EM, Zaugg SD, Barber LB (2002) Buxton HT (2002), Pharmaceuticals, hormones, and other organic wastewater contaminants in US streams, 1999-2000: a national reconnaissance. Environ Sci Technol 36:1202-1211

Koudelka-Hep M, Rooij N, Strike D (1997) Immobilization of enzymes on microelectrodes using chemical crosslinking. In: Bickerstaff $G$ (ed) Immobilization of enzymes and cells. Methods in biotechnology, vol 1. Humana Press, New York, USA, pp 83-85. doi:10.1385/0-89603-386-4:83

Koyama S, Aizawa M (2008) Physical modulation of cellular information networks. In: Artmann GM, Chien S (eds) Bioengineering in cell and tissue research. Springer, Berlin, Heidelberg, pp 37-61. doi:10.1007/978-3-540-75409-1_3

Laurell T, Rosengren L (1994) A micromachined enzyme reactor in $<110>$-oriented silicon. Sensor Actuat B Chem 19:614-617. doi:10.1016/0925-4005(93)01112-H

Li MH (2008) Effects of nonionic and ionic surfactants on survival, oxidative stress, and cholinesterase activity of planarian. Chemosphere 70:1796-1803. doi:10.1016/j.chemosphere.2007.08.032

Marie R et al (2006) Immobilisation of DNA to polymerised SU-8 photoresist. Biosens Bioelectron 21:1327-1332. doi:10.1016/j. bios.2005.03.004

Martinoia S, Meloni M, Parodi MT, Tedesco M, Ciccarelli C, Grattarola M (1993) Early detection of cell metabolism with a silicon microsensor. Cytotechnology 11:S86-S88. doi:10.1007/ BF00746064

Narang U et al (1994) Glucose biosensor based on a sol-gel-derived platform. Anal Chem 66:3139-3144. doi:10.1021/ac00091a023

National Poisons Information Service Annual Report (2011) http://www. npis.org/NPISAnnualReport2010-11.pdf. Accessed 11 May 2014
Niwa O, Horiuchi T, Torimitsu K (1997) Continuous monitoring of L-glutamate released from cultured nerve cells by an online sensor coupled with micro-capillary sampling. Biosens Bioelectron 12:311-319. doi:10.1016/S0956-5663(96)00072-3

Queensland Govermental Public Health Guidance Note (2002) http:// www.health.qld.gov.au/ph/documents/ehu/2689.pdf. Accessed 11 May 2014

Rowden AK, Norvell J, Eldridge DL, Kirk MA (2005) Updates on acetaminophen toxicity. Med Clin N Am 89:1145-1159. doi:10.1016/j.mcna.2005.06.009

Shah AD, Wood DM, Dargan PI (2011) Understanding lactic acidosis in paracetamol (acetaminophen) poisoning. Br J Clin Pharmacol 71:20-28. doi:10.1111/j.1365-2125.2010.03765.x

Strike DJ, Thiébaud P, van der Sluis AC, Koudelka-Hep M, de Rooij NF (1994) Glucose measurement using a micromachined open tubular heterogeneous enzyme reactor (mother). Microsyst Technol. doi:10.1007/BF01367760

Strike DJ, Fiaccabrino GC, Koudelka-Hep M, de Rooij NF (2000) Enzymatic microreactor using Si, glass and EPON SU-8. Biomed Microdevices 2:175-178. doi:10.1023/A:1009972210811

Talaei S (2013) Microengineered analytical tools for cell-based studies in environmental monitoring, pharmacology and neuroscience. Dissertation, Ecole Polytechnique Fédérale de Lausanne

Talaei S, Frey O, Psoma S, van der Wal PD, de Rooij NF (2010) Smart SU-8 pillars implemented in a microfluidic bioreactor for continuous measurement of glucose. Procedia Eng 5:448-451. doi:10.1016/j.proeng.2010.09.143

Talaei S, van der Wal PD, de Rooij NF (2011) Microfluidic approach for simultaneous measurement of choline and glutamate neurotransmitters in in vitro monitoring of neural cells. In: Proceedings of the 15th MicroTAS conference, USA, 130-132

Talaei S, van der Wal PD, Ahmed S, Giazzon M, de Rooij NF (2012) Cell metabolism monitoring using a microfluidic cartridge with enzyme-based microreactors. In: Proceedings of the Biosensors conference XXII, Mexico

Thedinga E et al (2007) Online monitoring of cell metabolism for studying pharmacodynamic effects. Toxicol Appl Pharmacol 220:33-44. doi:10.1016/j.taap.2006.12.027

Thomas N, Lähdesmäki I, Parviz B (2011) Photoresist-based integration of enzyme functionality into MEMS. Microsyst Technol 17:1505-1510. doi:10.1007/s00542-011-1333-8

Tian F, Gourine AV, Huckstepp RTR, Dale N (2009) A microelectrode biosensor for real time monitoring of 1-glutamate release. Anal Chim Acta 645:86-91. doi:10.1016/j.aca.2009.04.048

Updike SJ, Hicks GP (1967) The enzyme electrode. Nature 214:986-988

Vasylieva $\mathrm{N}$ et al (2011) Covalent enzyme immobilization by poly (ethylene glycol) diglycidyl ether (PEGDE) for microelectrode biosensor preparation. Biosens Bioelectron 26:3993-4000. doi:10.1016/j.bios.2011.03.012

Vojinović V, Calado CR, Silva AI, Mateus M, Cabral JMS, Fonseca LP (2005) Micro-analytical GO/HRP bioreactor for glucose determination and bioprocess monitoring. Biosens Bioelectron 20:1955-1961. doi:10.1016/j.bios.2004.08.015

Wiest J, Schmidhuber M, Ressler J, Scholz A, Brischwein M, Wolf B (2005) Cell based assays for diagnostic and therapy on multiparametric biosensor chips with an intelligent mobile lab. IFMBE Proc 10:132-135

Yang B, Dukkipati VR, Li D, Cardozo BL, Pang SW (2007) Stretching and selective immobilization of DNA in SU-8 micro- and nanochannels. J Vac Sci Technol B 25:2352-2356. doi:10.1116/1.2806975

Yotter RA, Wilson DM (2004) Sensor technologies for monitoring metabolic activity in single cells-part II: nonoptical methods and applications. IEEE Sens J 4:412-429 